\title{
THINNING AND RUPTURE OF A THIN LIQUID FILM ON A HEATED SURFACE
}

\author{
Progress Report \\ for Period Oct. 1, 1989 - Sept. 30, 1990 \\ S. G. Bankoff and S. H. Davis \\ Northwestern University \\ Evanston, IL 60108-3120
}

May 1992

Prepared for:

The U. S. DEPARTMENT OF ENERGY

AGREEMENT NO. DE-FG02-86ER 13641

\section{NOTICE}

This report was prepared as an account of work sponsored by the United States Government. Neither the United States nor the Department of Energy, nor any of their employees, nor any of their contractors, subcontractors, or their employees, makes any warranty, express or implied, or assumes any legal liability or responsibility for the accuracy, completeness, or usefulness of any information, apparatus, product or process disclosed or represents that its use would not inîringe privately-owned rights. 


\begin{abstract}
The objective of this work continues to be the study the dynamics, stability, and rupture (including contact line motions) of thin liquid films, especially with heat and/or mass transfer.

Following the publication of a comprehensive paper on thin-film stability and rupture, taking into account evaporation (condensation), thermocapillarity, surface tension, vapor recoil, van der Waals forces, and mass loss (gain), two follow-up papers have appeared. The first examines the conditions for a non-uniformly-heated liquid film to rupture, owing to thermocapillarity, while the second reports experimental results in excellent agreement with the theory. This is the first direct confirmation of lubrication theory on non-isothermal free-surface problems.
\end{abstract}

Another paper extends some previous results to the case where the viscosity of the liquid is a function of temperature. By proper rescaling, it is shown that the evolution equation can be transformed into the constant-viscosity case, so that previous results can be applied directly.

Another paper considers the nonlinear growth, stecpening, and wavebreaking of an isothermal thin liquid fi'.n draining down an inclined plate. The competition between mean flow and evaporation gives important morphological changes that control the heat-transfer process in the wavy regime. A number of other results were obtained. 
The objective of this work continues to be the study the dynamics, stability, and rupture (including contact line motions) of thin liquid films, especially with heat and/or mass transfer. A great deal has been accomplished, as evidence by the reference list, and the accompanying reprints and manuyscripts. The results can be summarized as follows:

1. Following the publication in JFM (Burelbach, Bankoff and Davis, 1988) of a comprehensive 31-page paper on thin-film stability and rupture, taking into account evaporation (condensation), thermocapillarity, surface tension, vapor recoil, van der Waals forces, and mass loss (gain), two follow-up papers (Tan. Bankoff and Davis 1990, and Burelbach, Bankoff and Davis, 1990) have appeared. The first examines the conditions for a non-uniformly-heated liquid film to rupture, owing to thermocapillarity, while the second reports experi- mental results in excellent agreement with the theory. This is the first direct confirmation known to us of lubrication theory on non-isothermal free-surface problems.

2. Another follow-up paper (Reisfeld and Bankoff, 1990) extends some of the previous results to the case where the viscosity of the liquid is a function of temperature. By proper rescaling, it is shown that the evolution equation can be transformed into the constant-viscosity case, so that previous results can be applied directly. This is a useful result for thin films of temperature-sensitive liquids.

3. Another follow-on paper considers the nonlinear growth, steepening, and wavebreaking of an isothermal thin liquid film draining down an inclined, plate (Joo, Bankoff and Davis, 1990a). It is shown (Joo, Davis, and Bankoff (1990a) that wavebreaking can be predicted directly from the nonlinear evolution equation, without making an ad hoc assumption concerning surface tension effects (Rosenau and Oron, 1989). This evolution equation has been extended to include effects of evaporation, given that the plate is heated. The competition between mean flow and evaporation gives important morphological changes that control the heat-transfer process in the wavy regime (Joo, Davis and Bankoff 1990b).

4. The spreading of a liquid drop on a heated surface has been shown to depend strongly on thermocapillarity (Ehrhard and Davis, 1989). A zero contact-angle drop can be made to stop spreading by heating the plate. A finite contact-angle drop can be made to spread to infinity by sufficient cooling. Hence, the spreading rates can be controlled by temperature manipulation.

5. Spin coating of a rotating horizontal surface by a thin, evaporating polymer-solvent film is used widely in the manufacture of computer chips and microelectromechanical components. The problem is complicated by the strong dependence of solution viscosity on the solvent concentration close to the gel point. All previous analyses have assumed that surface waves damp out quickly, so that only the thickness of the film as a function of time and the process conditions need be considered. We have examined this assumption in detail, and find that there is a transiently-stable regime, in which disturbance waves are initially magnified before being damped out by viscous effects. It is possible for these waves to be "frozen in" by rapid evaporation from the surface, particularly under conditions of low initial solute concentrations. These surface waves can lead to pinholes in the subsequent baking of the film to remove residual traces of solvent, particularly for very thin films (less than 0.5 microns) (Reisfeld, Bankoff and Davis, 1990a,b). 
6. The stability of a heated liquid film subjected to surface tension and van der Waals forces was examined for the case where the viscosity depends on temperature. In the limits of very large and very small Biot numbers, the evolution equation can be rescaled to give the Williams and Davis equation of constant viscosity (1982). Variable viscosity is thus found to reduce the rupture time relative to the constant-viscosity result (Reisfeld and Bankoff 1990).

\section{Personnel:}

S. G. Bankoff and S. H. Davis each spent approximately one month during the summer and one month during the academic year on this work. 


\section{References}

Burelbach, J. P., Bankoff, S.G. and Davis, S.H., (1988), "Nonlinear stability of evaporating/condensing films", J. Fluid Mechanics, vol. 195, pp. 463-494.

Burelbach, J. P., Bankoff, S.G. and Davis, S.H., (1990), "Steady therrnocapillary flows of thin liquid layers. II. Experiment", Phys. Fluids A, vol. 2, pp. 322-333.

Ehrhard, P. and Davis, S.H., (1989), "Non-isothermal spreading of liquid drops on horizontal plates", submitted to J. Fluid Mechanics; also Tech. Rpt. 8920, Applied Mathematics, Northwestern University.

Joo, S.W., Davis, S. H. and Bankoff, S.G., (1990a), "On falling-film instabilities and wave breaking", to be submitted to Phys. Fluids A; also Tech. Rpt. No. 8924, Applied Math, Northwestern University.

Joo, S.W., Davis, S. H. and Bankoff, S.G., (1990b), "Long-wave instabilities with heat transfer: A two-dimensional theory", to be submitted to J. Fluid Mechanics.

Reisfeld, B., Bankoff, S.G. and Davis, S.H., (1989a), "The dynamics and stability of liquid films during spin coating. Part 1. Films with constant rates of evaporation or absorption", submitted to J. Applied Physics.

Reisfeld, B., Bankoff, S.G. and Davis, S.H., (1989b), "The dynamics and stability of liquid films during spin coating. Part 2. Films with unit order and large Peclet numbers", submitted to J. Applied Physics.

Rosenau, P. and Oron, A., (1989), "Evolution and breaking of liquid film flowing on a vertical cylinder", Phys. Fluids A, vol. 1, pp. 1763-1766.

Tan, M.J., Bankoff, S.G. and Davis, S.H., "Steady thermocapillary flows of thin liquid layers. I. Theory", Physics of Fluids A, vol. 2, pp. 313-321 (1990). 

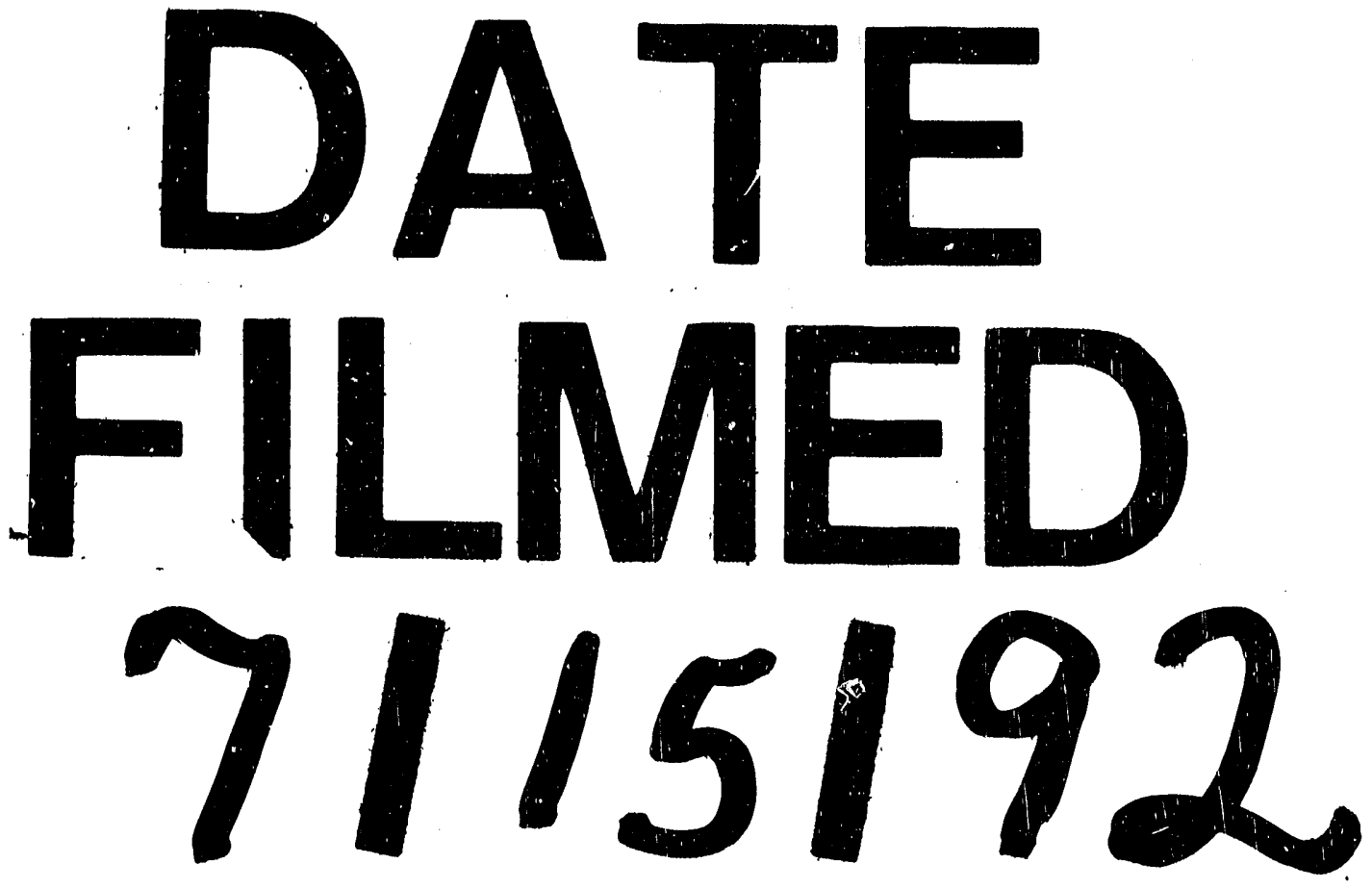
